\title{
Study of the Influence of Two-child Policy on English Teachers in Primary Schools
}

\author{
Based on the Case of Xi'an City
}

\author{
Zhengya Li \\ School of Foreign Languages \\ Xi'an University \\ Xi'an, China 710065
}

\begin{abstract}
The two-child policy has aroused tremendous attention of the public. Some researchers have explored its influence on compulsory education. This study attempted to present its influence on English language teachers in primary schools. The survey of 343 samples and interview of 7 principals reveal that the present situation if of grave concern. There is a severe shortage of English language teachers, and much disruption has been identified in the team of English language teachers, also some significant negative influence has been found in English teaching and school administration. In responding to these pressing problems, three suggestions were put forward for improvement in English teaching.
\end{abstract}

Keywords-two-child policy; English teachers in primary school; school administration

\section{INTRODUCTION}

In recent years, the basic education has made tremendous efforts to improve education quality and opportunities all over the country, they have adopted the policies like setting up branch schools, innovating old schools, updating teaching facilities, hiring more graduates, inviting famous teachers, promoting professional development among teachers, and so on. Elementary school students and their parents have witnessed the improvement, though there are still some fields left uncovered. The two-child policy has been proposed and implemented in China since the 3rd Plenary Session of 18th CPC Central Committee, which has great influence on the population number and leads to the rapid increase of school enrollment and school development. At the same time, it is discovered that the female population in primary schools is also planning to have the second child. It is well known that primary schools have a dominant population of female teachers, and most of the newly-hired teachers are female. Newly hired teachers need to have their first child, and the experienced teachers also plan to have the second child, which pose a great difficulty and challenge to the present primary schools.

The condition is even worse in the team of English language teachers, which is dominantly comprised of female

Fund project: Xi'an Social Science Fund Project of 2016: Research on the Development of Basic English Education Based on the "Two Children Age" (16WL01) teachers. Some of them just walked out of the college and they need opportunities and time for professional development, some of them plan to get married and have their first child, and some of them plan to have their second child. On one hand, more students of the baby boom will enter the primary schools; on the other hand the present team of English language teachers is unsteady, they may leave their teaching posts for the first or second child. Evidently, in order to ensure the sustainable quality of English teaching it is urgent and necessary for the primary schools and schools of education to make early preparation in English teaching, cultivation of pre-service English language teachers, designing courses for the potential teachers, and promoting professional development in-service teachers. Pressing by this severe circumstance, this study attempted to survey the English language teaching team in primary schools in Xi'an, summarize the findings in explaining the present situation, and put forward some suggestions for future research.

\section{LITERATURE REVIEW}

The influence of two-child policy is still a new issue in basic education, though there is a bourgeoning and hot discussion in newspapers and new media. The studies in CNKI revealed that there are only 17 pieces of articles centering on the relationship between the two-child policy and education. In particular, four of them have probed into its influence on compulsory education, seven of them have studied its influence on pre-school education, and the rest are not substantially related. The existing four articles have pointed out the gap between the present team of teachers and the expectation on the teachers, which is aggravated by the potential number of teachers who plan to have a second child. Some measures have been presented and adopted, like transferring teachers from the schools with less students, closing down those primary schools have not enough students, investing more fun into basic education (Qian Lu, 2015), providing more opportunities to teachers of remote and rural schools (Li, Yang \& Gong, 2017), and setting up more primary schools to the neighboring community.

Though the present research on this issue is scant, it has aroused certain awareness of this problem and much academic attention to the needs of teaching team in primary 
schools. Meanwhile, it can also be claimed that the existing literature is concentrating on the general situation of challenges faced by compulsory education, and the primary schools have identified this pressure and dilemma. However, fewer efforts have been devoted to understanding the pressure posed to the specific subjects in certain cities, especially English language subject. To most primary schools, two-child policy has left them with the problem of maintaining enough quality teachers of English language; while to schools of education it is a potential opportunity of development. The schools of education and schools of foreign languages can work out this problem through certain programs with primary schools and make their contribution to the local basic education, which in turn highlights the significant role of school of education and extend their function in satisfying the needs of local and national primary schools.

\section{FINDINGS OF THE SURVEY AMONG ENGLISH}

\section{LANGUAGE TEACHERS OF XI"AN PRIMARY SCHOOLS}

In order to obtain a deep and detailed understanding of English language teachers in Xi'an primary schools, this study conducted a survey among 343 English language teachers of primary schools in Xi'an and also interviewed 7 principals about the challenges brought by two-child policy. The analysis of the survey and interviews have revealed three grave concerns in the team of English language teacher, namely radical shortage of English language teachers in primary schools, disruption caused by maternity leave of English language teachers, and negative influences on English teaching and school administration.

\section{A. Radical Shortage of English Language Teachers in Primary School}

Before the two-child policy, the primary schools were pressed by the rapid expansion of urbanization and increasing school enrollment needs. On one hand, there is an ever-growing need for English language teachers; on the other hand the number of teachers was not increased accordingly. Some primary schools complained in the interview that they failed to recruit enough qualified teachers, while others complained about the numbers assigned by the local educational department were not sufficient for them to maintain.

The survey identified that the ratio of female and male among English language teachers in some schools is 9:1. Among all the 343 surveyed teachers, there are only 31 males, less than $10 \%$ of the total number. The high percentage of female teachers inevitably will lead to the severe shortage of teaching team, when they are encouraged by the two-child policy.

\section{B. Disruption Caused by Maternity Leave of English \\ Language Teachers}

The survey and interviews also presented that the average age of all the surveyed female teachers are 32.6, which indicated most of them are in their fertile period physically. If they plan to have the second child, the normal teaching arrangement will naturally be disrupted. In terms of professional development, these English language teachers have just accumulated teaching experience and their awareness of self-improvement is in the germination stage. Their maternity leave will also disrupt their own professional development. Both of the disruptions will disturb the development, and even the daily management of the schools. The students will be the direct victim of this shortage.

\section{Negative Influence on English Teaching and School Administration}

The influence of two-child policy on primary education is naturally reflected in English teaching and school administration. For students, they need a period of time to adjust themselves to their English teachers, in particular, their teaching style and accent. When their teachers leave for maternity, they will have to adapt themselves again to the new teacher. This is not the end. When their teacher comes back after the maternity leave, they have to shift themselves again, which is hard for the students in their English study. For the teachers, after their maternity leave, they have two children to take care of. Moreover, they have to support their families with more efforts and energy. The entire combining factor will stifle their enthusiasm, eagerness and confidence in professional development, which will correspondingly undermine the administration and reputation of the schools. The unsteady team of English language teachers will make the daily administration a hard work to maintain, and distort some development plans of the primary schools.

\section{SugGeStion FOR MAINTAINING A BODY OF SUFFICIENT QUALIFIED ENGLISH LANGUAGE TEACHERS}

The two-child policy, coupled with rapid urbanization, has pushed the educational departments, primary schools and schools of education to confront with the soaring needs of qualified English language teachers. Their joint efforts are needed to prepare for the challenge. Through the analysis of the present pressing situation, four suggestions were put forward to mitigate the tough situation.

\section{A. Cultivating a Team of General-subject Teachers}

School of education and School of foreign languages used to provide general-subject major for educational departments and primary school. The graduates of that time can teach Chinese, Math, Science and other subjects. Whenever there was a lack of teachers of certain subjects, it was much convenient to find a substitute teacher. Graduates of present university, though they have more shining academic background and professional knowledge, have been confirmed as having less competent in teaching practice.

Therefore, it is feasible and advisable to have general subject major in universities. When the graduates are competent in teaching Chinese, Math, English, and other subjects, they can fill the vacant position when the teachers are away on maternity leave. It can levitate the deteriorating situation with a relatively stable team of English language teachers. Meanwhile, the universities are expected to provide more opportunities for them to accumulate teaching 
experience, so that their period of developing can be shortened. Educational departments and primary schools can save enough time for cultivating experienced English language teachers.

\section{B. Providing more Flexible Professional Development Program for In-service Teachers}

Profession development for the in-service teachers often happened in traditional forms, like attending lectures, teaching and research meetings, face-to-face discussion in the office. The English language teachers on maternity leave have immense and unimaginable difficulty in attending these meetings and discussion. Educational department and primary schools are supposed to make some adjustments as a respond to the two-child policy. In particular, information technology and mobile technology can be employed to promote and extend the scope of professional development, including teacher leadership. (Nie, 2016) The teachers on maternity leave can still attend the seminars and conference, and they can also join the discussion synchronously and asynchronously. Though they are not at schools, they can make an effective use of the maternity leave for their professional development. The English language teachers will not worry about their professional development and the primary schools' plan and arrangement for professional development will not be interrupted, the schools can still enjoy a highly competent team of English language teachers.

Mobile technology and data science can also break through the boundaries of professional development, through introducing nationally and internationally famous experts, and bring experienced teachers all over the country together for sharing and improving. In-service English language teachers can avoid detours in seeking their professional development with the help of mobile technology. Their time and efforts can be saved for more efficient use. In turn, primary school students can enjoy the benefits of their teachers' professional development directly.

\section{Emphasizing the Teaching Practice among Pre-service Teachers of English Languages}

The schools of education and the schools of foreign studies tend to set aside half of the term, or the whole term for teaching practice. Sometimes it is no unusual to discover that the teachers will lecture them on how to teach in primary schools. More opportunities and efforts can still be channeled into observing classroom, and learning to reflect timely on improving the syllabus, teaching design, teaching plan, course design, and activity arrangements. Hand-on experience can contribute efficiently to the graduates' confidence-building.

At the same time, the graduates are advised to hone their teaching skills and experience in the classrooms as student teachers. Primary schools and the universities should cooperate with each other to set up teaching practice center in the primary schools, so that the graduates can learn and grasp the essence of classroom teaching efficiently and effectively.

\section{CONCLUSION}

The influence of two-child policy on basic education, particularly on English language teachers has been acknowledged and increasingly researched. In respond to the severe shortage of teachers, and vacuum gap of professional development, three suggestions are put forward in this study for cultivating a team of general-subject teachers with the employment of information technology and mobile technology. Joint efforts are also expected from the primary schools, local educational governments, and the universities. The findings and suggestions are mainly based on the survey of limited number of teachers and primary schools, which may provide an insight into the truth of its influence. Future research on English language teachers of primary schools in other cities or in the whole province is expected to provide detailed information for decision-making in educational department.

\section{REFERENCES}

[1] Li, L., Yang, S. G, \& Gong S. The Allotment of Kindergarten and Compulsory Education Resources in Chongqing. Village Economy, 2017, (04), 112-128.

[2] Nie, Y. J. Study of Educational Leadership Research in Western Countries. Modern Education Science, 2016, (04), 122-126.

[3] Qian, L. The Influence of Two-child Policy on Compulsory Education in Beijing, Manager's Journal, 2015, (06), 131. 